\title{
Can increased vigilance for chronic kidney disease in hospitalised patients decrease late referral and improve dialysis-free survival?
}

\author{
M. De Wilde*, M. Speeckaert and W. Van Biesen
}

\begin{abstract}
Background: Insufficient vigilance for renal insufficiency is associated with late referral, increased morbidity and mortality. The present study examines whether increased vigilance for chronic kidney disease (CKD) leads to quicker referral to and better follow-up by a nephrologist, and whether it is associated with an improved outcome.

Methods: Patients with an eGFR $<45 \mathrm{ml} / \mathrm{min} / 1.73 \mathrm{~m}^{2}$ during hospitalisation at the Ghent University Hospital were enrolled during a period of 100 days. The patients were interviewed about their awareness of CKD. Both the patients and their general practitioner were subsequently informed about CKD. The primary endpoint was the number of patients referred for nephrological follow-up within three months. The secondary endpoint was need for dialysis and mortality from any cause one year after inclusion.
\end{abstract}

Results: Of the 72 included patients, 54 had proven CKD, with eGFR consistently $<45 \mathrm{ml} / \mathrm{min} / 1.73 \mathrm{~m}^{2}$ during at least three months before inclusion. Merely $65 \%$ was aware of having CKD and only $41 \%$ was in regular nephrological follow-up. After intervention, the percentage of patients with CKD in follow-up increased from $41 \%$ to $71 \%$ ( $p=0.002$ ). The proportion reaching the secondary endpoint was significant lower in the patients who were referred quickly than in those who were not $(p=0.015)$. Similarly, the proportion was significant lower in the patients who received nephrological follow-up than in those who did not $(p=0.006)$.

Conclusion: Vigilance for CKD is poor. Simple interventions to augment the vigilance for CKD, as presented in this study, lead to a quicker referral to and follow-up by a nephrologist, which may result in better outcome.

Keywords: Care path, Chronic kidney disease, Dialysis-free survival, Early referral, Follow-up, Mortality, Vigilance

\section{Background}

Early detection, follow-up and treatment of CKD patients reduce the morbidity and mortality and delay the progression of renal failure $[1,2]$. Two thirds of the patients with CKD stages 3, 4 or 5 require one or more medical interventions or therapy adjustments, including a better control of arterial hypertension, correction of anaemia, management of mineral bone disorders or discontinuation of nephrotoxic medications [3-7].

Active participation of patients in their own care is critical $[8,9]$, but may be limited by the lack of

\footnotetext{
* Correspondence: maartendewilde@live.be

Department of Nephrology, Ghent University Hospital, De Pintelaan 185, 9000 Ghent, Belgium
}

(c) The Author(s). 2018 Open Access This article is distributed under the terms of the Creative Commons Attribution 4.0 International License (http://creativecommons.org/licenses/by/4.0/), which permits unrestricted use, distribution, and reproduction in any medium, provided you give appropriate credit to the original author(s) and the source, provide a link to the Creative Commons license, and indicate if changes were made. The Creative Commons Public Domain Dedication waiver (http://creativecommons.org/publicdomain/zero/1.0/) applies to the data made available in this article, unless otherwise stated.

awareness and understanding of CKD [10], ensuing in late referral [9]. A late referral to a multidisciplinary nephrology team is associated with a worse outcome after the start of dialysis and decreases the access to kidney transplantation [11]. Longer and more intense nephrological follow-up of patients who eventually undergo dialysis is commensurate with better survival $[9,11-13]$. In Belgium, a care path for chronic renal insufficiency was developed in 2009 by the National Institute for Health and Disability Insurance, in order to tackle CKD in a multidisciplinary way and increase the vigilance for CKD. Nevertheless, screening for renal insufficiency is presently still substandard, even in patients at risk [11]. The vigilance for renal insufficiency is still insufficient in general practitioners [14-16] as well as in medical 
specialists [5, 17], leading to delayed diagnosis and late referral to a nephrologist [18], which can result in inadequate treatment $[16,19,20]$ with possible impact on morbidity and mortality [21].

The goal of the present study was to examine if an increased vigilance for CKD in hospitalised patients results in a quicker referral to the nephrology outpatient clinic, a better follow-up and finally an improved outcome. More specifically, we explored whether there was a difference in dialysis-free survival and mortality rate.

\section{Methods}

The present study was a single center study performed in the Ghent University Hospital (Belgium). Subjects were enrolled over a period of 100 days, between November 2013 and February 2014. Patients, hospitalised on a selected number of medical wards in the hospital (thoracic and vascular surgery, cardiac surgery, cardiology, endocrinology, infectious diseases, dermatology and geriatrics) with an eGFR $<45 \mathrm{ml} / \mathrm{min} / 1.73 \mathrm{~m}^{2}$ (according to CKDEPI), were identified on a daily basis by a computer query program. The following exclusion criteria were used: patients with advanced dementia, patients in a palliative situation or having an end-stage organ failure, patients receiving any form of renal replacement therapy (peritoneal dialysis, haemodialysis or kidney transplantation) and patients with acute kidney injury (AKI), documented by a recent blood analysis, taken less than 3 months before identification by the computer program, showing an eGFR $>60 \mathrm{ml} / \mathrm{min} / 1.73 \mathrm{~m}^{2}$.

All patients provided informed consent. An eGFR measurement predating the current test for at least 3 months was obtained through search in the health records or by contacting the general practitioner to define the CKD status of the patient. Patients were interviewed about their awareness of CKD, follow-up by a nephrologist and inclusion in a care path. Patients and their general practitioner were subsequently informed about renal insufficiency, the presence of CKD and the possibility of inclusion in a care path. Three and twelve months after inclusion in the study, we checked if the patient had received a consultation on the nephrology outpatient clinic and whether a care path was initiated by contacting their general practitioner and/or nephrology outpatient clinic. In addition, the evolution of the kidney function and the outcome (initiation of dialysis and mortality from any cause) were recorded.

The primary endpoint of this study was whether the increased vigilance for CKD led to a higher number of patients referred to a nephrology outpatient clinic (within three months), receiving follow-up by a nephrologist and included in a care path. The secondary endpoint of the study was a combined endpoint of need for dialysis and mortality from any cause, reached between three months and one year after inclusion in the study.

Statistical analyses were performed using MedCalc (MedCalc, Ostend, Belgium). Differences between groups were evaluated using the Student's t-test and the Fisher's exact test with a two-tailed $p$-value. A $p$-value $<0.05$ was considered a priori to be statistically significant.

\section{Results}

During the inclusion period, 115 patients were identified with an eGFR $<45 \mathrm{ml} / \mathrm{min} / 1.73 \mathrm{~m}^{2}$ (Fig. 1). A total of 43 patients were excluded: 3 patients already received dialysis, ten patients had advanced dementia, an end-stage organ failure or received palliative care and 30 patients had AKI. The final cohort thus consisted of 72 patients (51 males and 21 females, mean age: $76.6 \pm 8.5$ years) with a mean eGFR of $33.9 \pm 6.9 \mathrm{ml} / \mathrm{min} / 1.73 \mathrm{~m}^{2}$.

Fifty-four patients (54/72) had proven CKD with an eGFR consistently $<45 \mathrm{ml} / \mathrm{min} / 1.73 \mathrm{~m}^{2}$ during at least three months before inclusion, of which 36 had CKD stage 3b (eGFR: $30-45 \mathrm{ml} / \mathrm{min} / 1.73 \mathrm{~m}^{2}$ ) and 18 CKD stage 4 (eGFR: $15-30 \mathrm{ml} / \mathrm{min} / 1.73 \mathrm{~m}^{2}$ ). Only $65 \%(35 /$ 54) of patients with CKD stage $3 \mathrm{~b}$ or 4 were aware of suffering from renal failure. Half of the patients with CKD stage $3 \mathrm{~b}$ or $4(27 / 54)$ were never referred to a nephrologist, 9\% (5/54) was once referred to a nephrologist before but was no longer in follow-up, and only $41 \%$ $(22 / 54)$ was followed by a nephrologist on a regularly basis. The number of patients who consulted a nephrologist at least once $(13 / 18$ vs $14 / 36 ; p=0.042)$ or who were still followed by a nephrologist (11/18 vs $11 / 36 ; p$ $=0.042$ ) was significantly higher in the group of patients with CKD stage 4 in comparison with CKD stage $3 \mathrm{~b}$, respectively. In the group of 32 patients with CKD, who were not followed by a nephrologist before inclusion, only $22 \%$ (7/32) was visited by a nephrologist during their hospitalization on request of their treating physician. In five patients (5/54) follow-up after inclusion was not possible due to completion of the secondary endpoint or a palliative stage within three months after inclusion. None of them was in follow-up by a nephrologist before inclusion.

Eighteen patients (18/72) did not had a proven advanced CKD at the time of inclusion, but were possibly evolving into a CKD stage 3b. 16/18 patients had never consulted a nephrologist before and had no knowledge of any renal impairment. In six patients (6/18), followup after inclusion was not possible due to completion of the secondary endpoint or a palliative stage within three months after inclusion. Of the remaining 12 patients, six evolved to a CKD stage $3 \mathrm{~b}$.

Three months after inclusion (Fig. 2), 55 patients (mean age: $76.7 \pm 8.0$ years, $69 \%$ males) were diagnosed with CKD (mean eGFR: $34.5 \pm 7.0 \mathrm{ml} / \mathrm{min} / 1.73 \mathrm{~m}^{2}$ ). 


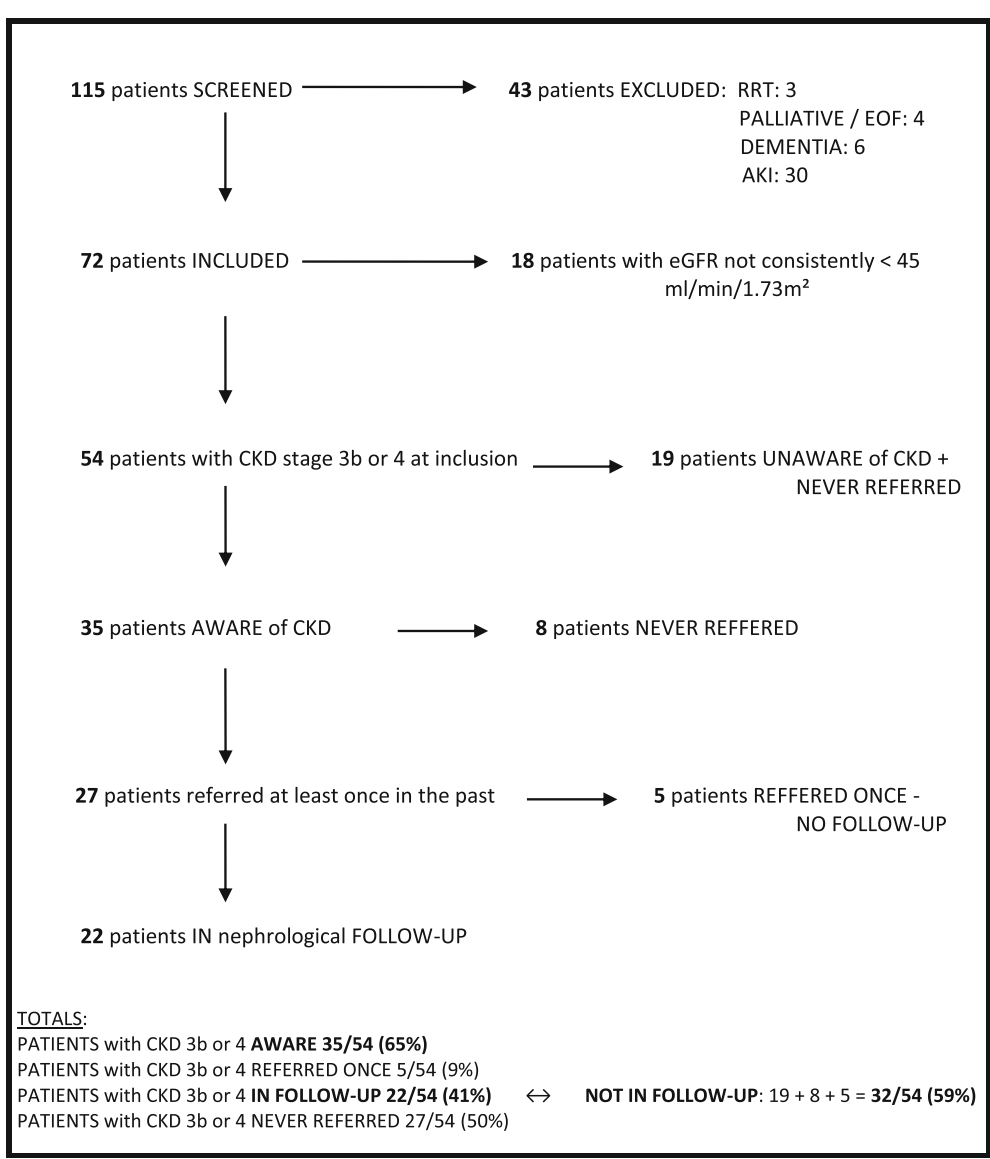

Fig. 1 Patient inclusion and vigilance for CKD. RRT, number of patients who received renal replacement therapy at time of inclusion; PALLIATIVE / EOF, number of patients in a palliative stage or with end organ failure at time of inclusion; DEMENTIA, number of patients with dementia at time of inclusion; AKI, number of patients with acute kidney injury

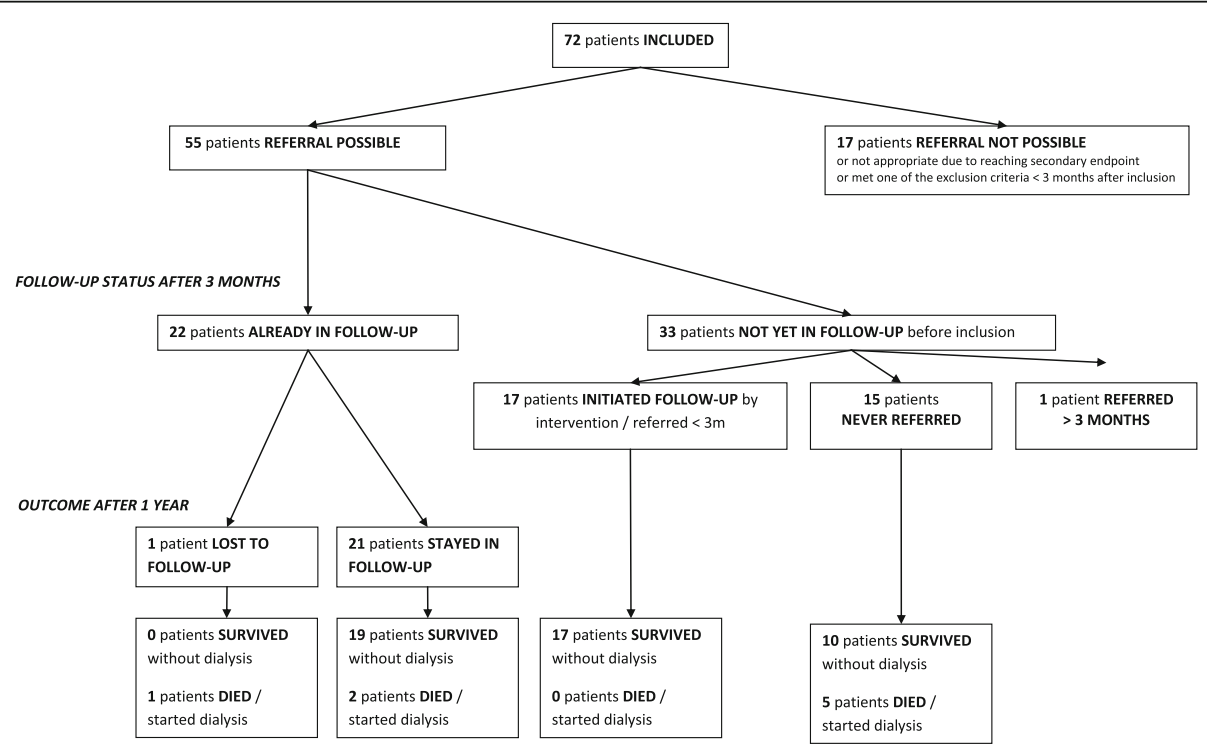

Fig. 2 Referrral status after 3 months and outcome after 1 year 
Seventeen patients (17/72) could not be referred or receive follow-up due to completion of the secondary endpoint or meeting one of the exclusion criteria within three months after inclusion. Thirty three $(33 / 55)$ patients were not yet followed by a nephrologist before their inclusion. The kidney function of the CKD patients who were not yet followed by a nephrologist before inclusion was significantly higher than the eGFR of the 22 patients who were already in follow-up $(36.9 \pm 5.8 \mathrm{ml} /$ $\min / 1.73 \mathrm{~m}^{2}$ vs $\left.30.9 \pm 7.1 \mathrm{ml} / \mathrm{min} / 1.73 \mathrm{~m}^{2}, p=0.001\right)$. More than half of these patients (17/33), consulted a nephrologist within three months after inclusion and started a care path. The proportion of patients in followup increased significantly from $41 \%(22 / 54)$ to $71 \%$ (39/ $55)$ within three months after inclusion $(p=0.002)$, an increase with $74 \%$. One patient consulted a nephrologist and started a care path six months after inclusion. The other fifteen patients (15/33) did not visit a nephrologist.

Comparison of the outcome one year after inclusion in CKD patients, not yet followed by a nephrologist before, shows that the need to start dialysis and/or mortality rate was significantly lower in the CKD patients who were referred quickly, stayed in follow-up and started a care path, compared with CKD patients who did not (0/ 17 vs $5 / 15 ; p=0.015)$. The compared groups did not differ significantly in gender, age, eGFR, number of patients with a therapy restriction or number of patients who stayed in a home care facility (Table 1). In addition, the need to start dialysis and/or mortality rate one year after inclusion was significantly lower in CKD patients who were followed at the nephrology department compared with the CKD patients who did not $(2 / 38$ vs $6 / 16 ; p=$ 0.006). Again, the compared groups did not differ significantly in gender, age, eGFR, number of patients with a therapy restriction or number of patients who stayed in a home care facility (Table 2).

Table 1 Characteristics and outcome of patients who were referred $<3$ months after inclusion vs patients who were never referred

\begin{tabular}{llll}
\hline & $\begin{array}{l}\text { Referred }<3 \\
\text { months }+ \\
\text { follow-up }\end{array}$ & $\begin{array}{l}\text { Not referred - } \\
\text { No follow-up }\end{array}$ & -value \\
\hline Total number of patients & 17 & 15 & \\
$\quad$ eGFR (mean) & $38.6(+/-4.4)$ & $35.8(+/-6.0)$ & $p=0.151$ \\
$\quad$ Age (mean) & $74.9(+/-8.4)$ & $78.7(+/-8.0)$ & $p=0.224$ \\
$\quad$ Males/females & $12 / 5$ & $10 / 5$ & $p=1.00$ \\
$\begin{array}{l}\text { Lives in care facility: } \\
\text { Yes/No }\end{array}$ & $0 / 17$ & $3 / 12$ & $p=0.092$ \\
$\begin{array}{l}\text { Therapy restriction: } \\
\text { Yes/No }\end{array}$ & $2 / 15$ & $2 / 13$ & $p=1.00$ \\
$\begin{array}{l}\text { Need of dialysis or } \\
\text { died within 1 year } \\
\text { after inclusion: Yes/No }\end{array}$ & $0 / 17$ & $5 / 10$ & $p=0.015$ \\
\hline
\end{tabular}

Table 2 Characteristics and outcome of patients who were in follow-up with a nephrologist vs patients who were not

\begin{tabular}{llll}
\hline & Follow-up & No follow-up & $P$-value \\
\hline Total number of patients & 38 & 16 & \\
eGFR (mean) & $34.6(+/-6.9)$ & $34.8(+/-7.2)$ & $p=0.931$ \\
Age (mean) & $75.6(+/-8.0)$ & $78.9(+/-8.1)$ & $p=0.168$ \\
$\quad$ Males/females & $27 / 11$ & $10 / 6$ & $p=0.540$ \\
$\begin{array}{l}\text { Lives in care facility: } \\
\text { Yes/No }\end{array}$ & $1 / 37$ & $3 / 13$ & $p=0.073$ \\
$\begin{array}{l}\text { Therapy restriction: } \\
\text { Yes/No }\end{array}$ & $4 / 34$ & $2 / 14$ & $p=1.00$ \\
$\begin{array}{l}\text { Need of dialysis or } \\
\text { died within 1 year } \\
\text { after inclusion: Yes/No }\end{array}$ & $2 / 36$ & $6 / 10$ & $p=0.006$ \\
\hline
\end{tabular}

\section{Discussion}

This study reveals that in patients admitted to a tertiary care hospital, CKD is unacknowledged in a substantial number of patients. These data are supported by previous findings in European populations. In the UK, nearly 85\% of patients with CKD, defined as a serum creatinine of $>$ $2.03 \mathrm{mg} / \mathrm{dl}$ in men and $>1.53 \mathrm{mg} / \mathrm{dl}$ in women, were not in follow-up [4]. In Northern Ireland, only a minority of patients with a serum creatinine $>1.7 \mathrm{mg} / \mathrm{dl}$ were referred to a nephrologist [22]. Also in Germany, relatively few patients (39\%) with CKD-stage 4 were followed with a nephrologist [23].

Vigilance for renal insufficiency increases significantly in more advanced CKD stages. Among patients with CKD stage 3b, 69\% was not followed by a nephrologist vs $39 \%$ among patients with CKD stage 4 . The observed difference in vigilance for CKD according to the CKD stage is consistent with the literature [19]. More than a third of the CKD patients in the present study were not aware of their renal insufficiency, although the kidney function was measured at previous time points. This is in line with the results of a British study, where $31 \%$ of the patients with CKD stage $3 \mathrm{~B}, 4$ or 5 were unaware of their disease [3].

The underlying reasons why advanced CKD remains out of scope in so many patients are presumably multifactorial (1): several guidelines concerning when to refer to a nephrologist offer conflicting information [24] or are subject to national $[25,26]$ or regional [27] related measures and agreements (2), these guidelines are often insufficiently known by clinical practioners $[17,19,21$, $28,29]$ and (3) the evidence of the published guidelines is rather scarce.

This study has succeeded to detect patients with advanced CKD not yet followed by a nephrologist, and to inform this group of patients and their general practitioners about renal insufficiency, the presence of CKD and the possibility for inclusion in a care path. In this 
way, the vigilance for renal insufficiency was augmented, creating a higher alertness for conditions interacting with a declining kidney function. In slightly more than half of the newly discovered patients with advanced CKD, a care path was initiated after discharge, leading to a significant augmentation of the number of patients with CKD in follow-up by a nephrologist.

In patients where the intervention did not lead to follow-up by a nephrologist, a significant higher need for dialysis and/or increased mortality rate in the year after inclusion was observed. This is in line with previous literature. In a prospective British study, CKD patients (serum creatinine $\geq 2.03 \mathrm{mg} / \mathrm{dl}$ in men and $\geq 1.53 \mathrm{mg} / \mathrm{dl}$ in women; equivalent to an eGFR $<43 \mathrm{ml} / \mathrm{min} / 1.73 \mathrm{~m}^{2}$ and a mean eGFR of $28.5 \mathrm{ml} / \mathrm{min} / 1.73 \mathrm{~m}^{2}$ ) who were not followed by a nephrologist, showed a significantly higher mortality [4]. In a retrospective study of CKD patients, defined as a serum creatinine of $>1.4 \mathrm{mg} / \mathrm{dl}$, a better survival of patients with CKD stage 3 and 4 was noted in those who received nephrology follow-up [30]. A similar finding was found in diabetic veterans with CKD stage 3 and 4 [31].

The majority of general practitioners feel that they have not received adequate training regarding time or indications for referral of patients with progressive kidney failure [32]. Increasing the vigilance for renal insufficiency as presented in this study is trying to provide a higher level of involvement and information, in both the patient and their physicians, with the goal of promoting compliance and follow-up.

Despite the fact that there was no statistically difference in age, gender or eGFR between the compared groups, despite the exclusion of patients with advanced dementia and patients in a final palliative situation or with an end-stage organ failure as well as the exclusion of patients who achieved the secondary endpoint during the first three months after inclusion, a selection bias could still be responsible for the difference in achieving the secondary endpoint. Nevertheless, the number of patients with a therapy restriction and the number of patients who stayed in a home care facility, did not differ significantly between these groups. The major limitation of the study is its observational nature. Although demographic, clinical and biochemical characteristics were similar between the groups, it is conceivable that more compliant patients are more likely to present for further follow-up. Poor compliance is responsible for $42 \%$ of the late referrals [33] and may have contributed to the observed differences in survival. In addition, the decision by physicians not to refer the patient for nephrological follow-up is often practiced for reasons of existing co-morbidities [34]. Since we did not correct for all comorbid conditions, comorbidity may have further biased the results at the disadvantage of the patients that were not referred. A further limitation is the small sample size and the single center design of the study. The present findings should therefore be confirmed in a larger multicenter study.

\section{Conclusion}

The vigilance for renal insufficiency of both general practitioners and medical specialists remains insufficient. By detecting and informing patients with advanced CKD, a higher awareness of the disease in both patients and physicians is obtained, leading to a significant quicker referral to and follow up by a nephrologist. The combined endpoint of mortality from any cause and the need for dialysis was significantly lower in patients who were referred early to the nephrology outpatient clinic and followed by a nephrologist.

\section{Abbreviations filtration rate \\ Acknowledgements \\ Not applicable. \\ Funding \\ Nothing to declare.}

AKI: Acute kidney injury; CKD: Chronic kidney disease; eGFR: Estimated glomerular

\section{Availability of data and materials}

The datasets used and/or analysed during the current study are available from the corresponding author on reasonable request.

\section{Authors' contributions}

MDW performed the study, analyzed and interpreted the patient data. MDW, MS and WVB commented, read and approved the manuscript.

\section{Ethics approval and consent to participate}

The study was approved by the ethical committee of the Ghent University Hospital.

Written informed consent was obtained in all participating patients.

\section{Consent for publication}

Not applicable

\section{Competing interests}

The authors declare that they have no competing interests.

\section{Publisher's Note}

Springer Nature remains neutral with regard to jurisdictional claims in published maps and institutional affiliations.

Received: 8 June 2017 Accepted: 12 March 2018

Published online: 02 April 2018

\section{References}

1. Jones C, Roderick P, Harris S, Rogerson M. An evaluation of a shared primary and secondary care nephrology service for managing patients with moderate to advanced CKD. Am J Kidney Dis. 2006:47:103-14.

2. Jones C, Roderick P, Harris S, Rogerson M. Decline in kidney function before and after nephrology referral and the effect on survival in moderate to advanced chronic kidney disease. Nephrol Dial Transplant. 2006;21:2133-43.

3. Mclntyre NJ, Fluck R, McIntyre C, Taal M. Treatment needs and diagnosis awareness in primary care patients with chronic kidney disease. Br J Gen Pract. 2012;62:227-32.

4. John R, Webb M, Young A, Stevens PE. Unreferred chronic kidney disease: a longitudinal study. Am J Kidney Dis. 2004;43:825-35.

5. McClellan WM, Knight DF, Karp H, Brown WW. Early detection and treatment of renal disease in hospitalized diabetic and hypertensive 
patients: important differences between practice and published guidelines. Am J Kidney Dis. 1997;29:368-75.

6. Gallieni M, De Nicola L, Santoro D, Meneghel G, Formica M, Grandaliano G, et al. Management of CKD-MBD in non-dialysis patients under regular nephrology care: a prospective multicenter study. J Nephrol. 2016;29(1):71-8.

7. Ingrasciotta Y, Sultana J, Giorgianni F, Fontana A, Santangelo A, Tari DU, et al. Association of individual non-steroidal anti-inflammatory drugs and chronic kidney disease: a population-based case control study. PLoS One. 2015;16:10(4)

8. Murray MA, Brunier G, Chung JO, et al. A systematic review of factors influencing decision-making in adults living with chronic kidney disease. Patient Educ Couns. 2009;76:149-58.

9. Obialo $\mathrm{Cl}$, Ofili EO, Quarshie A, Martin PC. Ultralate referral and presentation for renal replacement therapy: socioeconomic implications. Am J Kidney Dis. 2005;46:881-6.

10. Lopez-Vargas PA, Tong A, Howell M, Craig JC. Educational interventions for patients with CKD: a systematic review. Am J Kidney Dis. 2016;68:353-70.

11. Smart NA, Dieberg G, Ladhani M, Titus T. Early referral to specialist nephrology services for preventing the progression to end-stage kidney disease. Cochrane Database Syst Rev. 2014;6:CD007333.

12. Avorn J, Bohn RL, Levy E, Levin R, Owen WF Jr, Winkelmayer WC, et al. Nephrologist care and mortality in patients with chronic renal insufficiency. Arch Intern Med. 2002;162:2002-6.

13. Van Biesen W, De Vecchi A, Dombros N, Dratwa M, Gokal R, LaGreca G, et al. The referral pattern of end-stage renal disease patients and the initiation of dialysis: a European perspective. Perit Dial Int. 1999;19:S273-5.

14. Crinson I, Gallagher H, Thomas N, de Lusignan S. How ready is general practice to improve quality in chronic kidney disease? A diagnostic analysis. Br J Gen Pract. 2010;60:403-9.

15. Ryan TP, Sloand JA, Winters PC, et al. Chronic kidney disease prevalence and rate of diagnosis. Am J Med. 2007;120:981-6.

16. Minutolo R, DeNicola L, Mazzaglia G, et al. Detection and awareness of moderate to advanced CKD by primary care practitioners: a cross-sectional study from Italy. Am J Kidney Dis. 2008:52:444-53.

17. Agrawal V, Ghosh AK, Barnes MA, McCullough PA. Perception of indications for nephrology referral among internal medicine residents: a national online survey. Clin J Am Soc Nephrol. 2009:4:323-8.

18. Jungers P, Chauveau P, Descamps-Latscha B, et al. Age and gender-related incidence of chronic renal failure in a French urban area: a prospective epidemiologic study. Nephrol Dial Transplant. 1996;11:1542-154.

19. Morrow BD, Stewart IJ, Barnes EW, Cotant CL. Chronic kidney disease management in an academic internal medicine clinic. Clin Exp Nephrol. 2010;14:137-43.

20. Rothberg M, Kehoe E, Courtemanche A, et al. Recognition and management of chronic kidney disease in an elderly ambulatory population. J Gen Intern Med. 2008;23:1125-30.

21. Morosetti M, Gorini A, Costanzo AM, et al. Clinical management of nondialysis patients with chronic kidney disease: a retrospective observational study. Data from the SONDA study (survey of non-Dialysis outpAtients). Int J Nephrol Renovasc Dis. 2013;6:27-37.

22. Kee F, Reaney E, Savage G, O'Reilly D, Patterson C, Maxwell P, et al. Are gatekeepers to renal services referring patients equitably? J Health Serv Res Policy. 2007;12:36-41.

23. Riegel W, Hahn K, Kreutz R, et al. BENEFIT kidney-significance of a nephrology screening at intervention outset and therapy success. Dtsch Med Wochenschr. 2005;130:792-6.

24. De Coster C, McLaughlin K, Noseworthy TW. Criteria for referring patients with renal disease for nephrology consultation: a review of the literature. J Nephrol. 2010;23:399-407.

25. The National Institute for Health and Clinical Excellence. Chronic kidney disease: national clinical guideline for early identification and management in adults in primary and secondary care. London: NICE; 2008. https://www. nice.org.uk

26. Meijer L, Schellevis FG. Verwijzing van patiënten met chronische nierschade. Verschillen in verwijscriteria tussen ziekenhuizen. Ned Tijdschr Geneeskd. 2012;156(50):A5259.

27. Johnson DW, Atai E, Chan M, Phoon RK, Scott C, Toussaint ND, et al. KHACARI guideline: early chronic kidney disease: detection, prevention and management. Nephrology (Carlton). 2013;18:340-50.

28. Agrawal V, Ghosh AK, Barnes MA, McCullough PA. Awareness and knowledge of clinical practice guidelines for CKD among internal medicine residents: a national online survey. Am J Kidney Dis. 2008;52:1061-9.
29. Agrawal V, Agarwal M, Ghosh AK, Barnes MA, McCullough PA. Identification and management of chronic kidney disease complications by internal medicine residents: a national survey. Am J Ther. 2011;18:e40-7.

30. Orlando LA, Owen WF, Matchar DB. Relationship between nephrologist care and progression of chronic kidney disease. N C Med J. 2007;68:9-16.

31. Tseng CL, Kern EF, Miller DR, Tiwari A, Maney M, Rajan M, et al. Survival benefit of nephrologic care in patients with diabetes mellitus and chronic kidney disease. Arch Intern Med. 2008;68:55-62.

32. Campbell JD, Ewigman B, Hosokawa M, Van Stone JC. The timing of referral of patients with end-stage renal disease. Dial Transplant. 1989;18:660-86.

33. Jungers P, Zingraff J, Albouze G, Chauveau P, Page B, Hannedouche T, et al, Late referral to maintenance dialysis: detrimental consequences. Nephrol Dial Transplant. 1993;8:1089-93.

34. Wauters JP, Lameire N, Davison A, Ritz E. Why patients with progressing kidney disease are referred late to the nephrologist: on causes and proposals for improvement. Nephrol Dial Transplant. 2005;20:490-6.

\section{Submit your next manuscript to BioMed Central and we will help you at every step:}

- We accept pre-submission inquiries

- Our selector tool helps you to find the most relevant journal

- We provide round the clock customer support

- Convenient online submission

- Thorough peer review

- Inclusion in PubMed and all major indexing services

- Maximum visibility for your research

Submit your manuscript at www.biomedcentral.com/submit
Biomed Central 